\title{
HABERMAS E A EDUCAÇÃO: RACIONALIDADE COMUNICATIVA, DIAGNÓSTICO CRÍTICO E EMANCIPAÇÃO
}

\author{
ELDON HENRIQUE MÜHL*
}

\begin{abstract}
RESUMO: O objetivo deste trabalho é explicitar as implicações da teoria da racionalidade comunicativa e da teoria da modernidade de Habermas sobre o campo educacional. O texto desenvolve, inicialmente, as principais ideias sobre estas duas teorias, apresentando um breve diagnóstico da crise atual da racionalidade e da educação. Como referencial aparecem os dois conceitos centrais do autor: do mundo da vida e do sistema. Na sequência, é realizada a análise das implicações da teoria comunicativa no campo educacional, avaliando-se, do ponto de vista pedagógico, a eficácia das teses do pensador alemão. Destacam-se as consequências pedagógicas da mudança do paradigma da filosofia do sujeito para o paradigma da intersubjetividade, além do papel da filosofia nessa reconstrução. O objetivo é fundamentar uma proposta pedagógica crítica, tendo por base a Teoria da Ação Comunicativa de Habermas.
\end{abstract}

Palavras-chave: Ação comunicativa. Teoria da modernidade. Educação emancipadora. Habermas.

\section{HABERMAS AND EDUCATION: COMMUNICATIVE RATIONALITY, CRITICAL DIAGNOSIS AND EMANCIPATION}

ABSTRACT: This work tries to clarify the impacts of the theory of communicative rationality and Habermas' theory of modernity on the educational field. After developing the main ideas of both theories, it presents a brief diagnostic of the current crisis of rationality and education. Its references are two concepts that are central to the author: the world of life and the system. The text then analyzes the implications of the communicative theory in the educational field and evaluates the efficiency of the German thinker's theses from a pedagogical point of view. It highlights both the pedagogical consequences of the philosophical change from the paradigm of the philosophy of the subject to that of intersubjectivity and the role philosophy played in this reconstruction in order to found a critical pedagogical proposal based on Habermas' Theory of Communicative Action.

Key words: Communicative action. Theory of modernity. Emancipative education. Habermas. * Doutor em Educação e professor de Filosofia e Fundamentos da Educação da Faculdade de Educa-
ção da Universidade de Passo Fundo (UPF). E-mail: eldon@upf.br 


\section{HABERMAS ET L'ÉDUCATION: RATIONALITÉ COMMUNICATIONNELle, DIAGNOSTIC CRITIQUE ET ÉMANCIPATION}

RÉSUMÉ: Ce travail cherche à expliciter les implications de la théorie de la rationalité communicationnelle et de la théorie de la modernité de Habermas dans le champ de l'éducation. Ce texte développe les principales idées de la théorie de la rationalité communicationnelle et de la théorie de la modernité avant de présenter un bref diagnostic de la crise actuelle de la rationalité et de l'éducation. Deux concepts centraux de l'auteur servent de cadre de références : ceux de monde de la vie et de système. Suit une analyse des implications de la théorie communicative dans le champ de l'éducation qui évalue l'efficacité des thèses de ce penseur allemand du point de vue pédagogique. Le texte souligne les conséquences pédagogiques du changement de paradigme de la philosophie du sujet vers celui de l'intersubjectivité, outre le rôle de la philosophie dans cette reconstruction. Le but en est de fonder une proposition pédagogique critique ayant pour base la théorie de l'action communicative de Habermas.

Mots-clés: Action communicative. Théorie de la modernité. Éducation émancipatrice. Habermas.

\section{Razão comunicativa e emancipação}

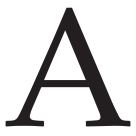

racionalidade é um dos temas centrais do projeto filosófico de Habermas, pois, segundo afirma, este é o problema que justifica a existência da filosofia: "Pode inclusive dizer-se que o pensamento filosófico nasce da reflexão sobre a razão corporificada no conhecimento, na linguagem e na ação. O tema fundamental da filosofia é a razão" (Habermas, 1987a, p. 15).

A preocupação de Habermas com a racionalidade liga-se ao objetivo que, desde o início, acompanha seu trabalho investigativo: reabilitar a ideia segundo a qual a razão é o principal recurso - senão o único - de que a humanidade dispõe para resolver seus conflitos e encontrar alternativas de solução para seus problemas.

As críticas desenvolvidas contra a razão, embora importantes, não podem nos levar a desacreditar do poder da razão de produzir saberes válidos e de possibilitar o surgimento de consensos razoáveis sobre nossa forma de ser e atuar no mundo. Para tanto, é preciso repensar a razão em sua constituição ampla e na forma como ela se realiza na prática concreta do dia a dia das interações humanas. A racionalidade deve ser entendida, antes de tudo, como a disposição dos sujeitos capazes de falar e de agir, de buscar um entendimento acerca do mundo, orientando-se "pelas pretensões de validade que estão assentadas no reconhecimento intersubjetivo" (Habermas, 2000, p. 437).

Habermas alerta insistentemente que a razão, além de se orientar por interesses técnico-instrumentais, orienta-se por interesses práticos e interesses emancipadores. 
Assim como Kant, ele identifica a existência de um sistema de regras a priori que torna possível o entendimento acerca das realidades e pode promover a emancipação dos indivíduos. Porém, enquanto em Kant essa condição é dada pela apercepção transcendental do eu penso, em Habermas realiza-se pela ação comunicativa de uma comunidade de falantes. Na teoria da interação, o sujeito transcendental de Kant é substituído pela comunidade comunicativa e as categorias do entendimento passam a ser entendidas como competências desenvolvidas pela espécie humana de produzir entendimentos. Daí a tarefa da pragmática universal de reconstruir e tornar explícitas essas estruturas profundas e universais da competência comunicativa da espécie humana. Escreve Habermas (2000, p. 415):

\begin{abstract}
O que antes competia à filosofia transcendental, a saber, a análise intuitiva da consciência de si, adapta-se agora ao círculo das ciências reconstrutivas, que, desde a perspectiva dos participantes de discursos e de interações, procuram tornar explícito o saber pré-teórico de regras de sujeitos que falam, agem e conhecem competentemente, recorrendo a uma análise das manifestações bem-sucedidas ou distorcidas. Visto que tais tentativas de reconstrução não se destinam mais a um reino do inteligível que está além dos fenômenos, mas ao saber de regras efetivamente praticado e sedimentado nas manifestações geradas segundo regras, anula-se a separação ontológica entre o transcendental e o empírico.
\end{abstract}

Ao conceber a razão como razão comunicativa, o autor assume a concepção de racionalidade como um processo que se desenvolve na intersubjetividade. Para ele, a diferença entre a filosofia da consciência e a teoria da racionalidade comunicativa não é apenas de conteúdo e de método, mas da natureza da própria razão. Esta, centrada no sujeito, é solitária e autorreferente e encontra a medida de validação dos seus saberes nos critérios de verdade e êxito. Sua intenção é o domínio teórico ou prático do objeto, segundo fins estabelecidos pelo próprio sujeito. Em contrapartida, a razão subjacente à linguagem é intersubjetiva e interativa e o saber que ela produz é mediado pela comunicação. A racionalidade do agir comunicativo "encontra sua medida na capacidade de os participantes responsáveis da interação orientarem-se pelas pretensões de validade que estão assentadas no reconhecimento intersubjetivo" (idem, ibid., p. 437).

Para Habermas, a racionalidade comunicativa é muito mais produtiva do que a racionalidade da subjetividade no esclarecimento das condições de possibilidade do conhecimento humano, pois, enquanto esta última é moldada por uma dimensão cognitivo-instrumental, aquela envolve um conceito procedural e inclui, além da dimensão instrumental, as dimensões prático-moral e estético-expressiva.

Para estabelecer as diferenças e revelar a necessidade de buscar um conceito ampliado de razão, o autor detalha as principais limitações da racionalidade centrada na subjetividade. A racionalidade subjetiva sustenta-se no pressuposto de que o 
sujeito tem primazia sobre o objeto, cabendo-lhe o controle teórico e prático sobre a natureza e sobre toda a realidade circundante. Por isso, Habermas considera que, nessa concepção de racionalidade, sempre prevalece o caráter instrumental da razão, uma vez que ela é reduzida a uma dimensão manipuladora e controladora. A subjetividade, nesse contexto, assume um papel constituinte do objeto, na medida em que determina o conteúdo e a forma do mesmo; o objeto é mera representação interna da razão e produto da ação da subjetividade sobre a natureza $\mathrm{O}$ critério de validação do conhecimento depende da clara e transparente representação dos conceitos do sujeito para o próprio sujeito. Em síntese, a consciência do sujeito sobre o mundo é autoconsciência. Nos termos do próprio autor, "trata-se da estrutura da auto-relação do sujeito cognoscente que se dobra sobre si mesmo enquanto objeto para se compreender como em uma imagem especular, justamente de modo 'especulativo'" (ibid., p. 28).

A racionalidade comunicativa se apresenta como uma alternativa crítica a essa concepção introspectiva e intuitiva do conhecimento. A concepção comunicativa de razão encontra nas expressões gramaticais elementos que tornam possível o conhecimento por atos de fala. A pragmática da linguagem parte do pressuposto de que é possível certificar-se da realidade externa e interna através da análise das representações e dos pensamentos, seguindo as formações gramaticais por meio das quais eles são expressos.

Para tanto, a linguagem deve ser entendida não apenas como um recurso de representação, mas como um recurso pragmático da interação dos seres humanos. Em vista disso, não basta analisá-la na sua estrutura lógico-formal, como o fazem os semanticistas, mas é preciso explicitar a natureza que ela apresenta no seu uso pragmático, através dos atos de fala. Em outros termos, deve-se levar em conta as relações que se estabelecem entre os sujeitos quando se referem ao mundo e agem interativamente, utilizando-se da linguagem. Isso representa avançar na compreensão do processo de constituição do mundo e no entendimento da construção dos saberes através da abordagem pragmática ou teórico-comunicativa da racionalidade.

Cabe destacar ainda que, para Habermas, a racionalidade comunicativa contém em si mesma um telos emancipador que torna possível a manutenção do poder transformador da razão. No telos da linguagem pragmática, o autor encontra elementos para restabelecer o poder da razão de normatizar e dar validade ao agir humano. "Vou desenvolver a tese", diz Habermas (1997, p. 300), “de que todo o agente que atua comunicativamente tem que empenhar, na execução de qualquer ato de fala, pretensões universais de validade e supor que tais pretensões podem desempenhar-se". Como falantes, os seres humanos participam de um entendimento racional e, no uso pragmático da linguagem, estabelecem tais entendimentos e constituem as estruturas do mundo da vida. 


\section{Teoria da modernidade em Habermas: racionalidade sistêmica, ra- cionalidade comunicativa e diagnóstico crítico da educação}

Para que possamos identificar as possíveis contribuições de Habermas para a reconstrução da teoria crítica e de um projeto emancipador da educação, precisamos nos remeter à teoria da modernização desenvolvida pelo autor e avaliar a produtividade desta no diagnóstico dos problemas da educação atual.

Habermas (1987b) desenvolve a teoria da modernidade pela ótica do confronto entre a razão que predomina no mundo da vida e a razão que orienta a ação sistêmica. Sistema e mundo da vida são duas esferas que se opõem; mas, ao mesmo tempo, são interdependentes, constituindo um complexo que determina a forma de ser da sociedade moderna. O mundo sistêmico, apesar de se apresentar como oposto ao mundo vital, tem sua origem vinculada ao mundo da vida e se mantém, ainda que de forma parasitária, dependente do agir comunicativo. O mundo sistêmico é decorrente da racionalização do mundo da vida e surge como um mecanismo redutor de carga que pesa sobre o agir comunicativo diante do esgotamento dos outros mecanismos de controle social. À medida que ele se torna mais complexo, tende a romper os seus vínculos com o mundo da vida, a substituir a comunicação pela linguagem por mecanismos de controle técnicos sob os auspícios do dinheiro e do poder, em detrimento dos demais componentes do mundo da vida. Quando o sistema se torna independente do mundo da vida e mais complexo, a dinâmica da influência entre ambos se modifica. Da situação inicial, em que o mundo da vida determina a estrutura sistêmica, com a complexificação social, os papéis se invertem e o sistema passa a reger o mundo da vida. Disso decorre o processo que Habermas denomina de "colonização do mundo da vida", cujo sintoma mais representativo é a sua instrumentalização e a restrição progressiva da comunicação através do domínio técnico e da violência estrutural. Em decorrência, o mundo da vida, de uma instância central, transforma-se em periférica diante da dominação que o sistema regido pelo dinheiro e pelo poder passa a exercer. A educação, intimamente atrelada ao mundo da vida, não deixa de sofrer as consequências de tal condicionamento.

Segundo Habermas, o mundo sistêmico possui mecanismos de regência e de controle, que favorecem a sua autorreprodução: o meio dinheiro, que rege o sistema economia, e o meio poder, que exerce a regulação do sistema político. Será através desses dois meios que o sistema fará suas tentativas de manter o controle social e a manipulação do mundo da vida; são eles que se transformarão nos instrumentos de substituição da comunicação interpessoal, manifestada através de intersubjetividades orientadas ao entendimento, pelos mecanismos sistêmicos da burocracia. $\mathrm{O}$ dinheiro torna-se o principal mecanismo de intercâmbio, transformando os valores de uso em valores de troca, o trânsito natural de bens em trânsito de mercadorias. 
O poder volta-se prioritariamente para a proteção sistêmica em detrimento das necessidades e demandas dos grupos sociais e dos indivíduos.

Habermas afirma que uma das mais importantes capacidades de o sistema interferir no mundo da vida revela-se na tendência à racionalização das normas por parte dos atores sociais. Essa racionalização está estreitamente relacionada com a formação dos valores culturais e da consciência moral. Dessa forma, estabelecendo e incutindo normas no comportamento individual de sujeitos dotados de consciência moral, os sistemas poder e dinheiro atuam no sentido de racionalizar também o mundo da vida. A escola é uma dessas instituições que, no entender de Habermas, serve para incorporar a racionalidade sistêmica atualmente dominante. Ao fazer isso, ela educa para a subserviência, reforça o controle e produz, em última instância, a própria violência.

A dominação sistêmica se torna efetiva na educação pela crescente influência da ideologia tecnocrática, implicando a eliminação da diferença entre práxis e técnica e tornando a relação entre os membros da comunidade escolar impessoal. Com efeito, o moderno Estado tecnocrático tem exigido o avanço da racionalidade instrumental e estratégica na escola, tornando-a uma entidade que é forçada a incorporar progressivamente a racionalidade instrumental em atendimento às exigências sistêmicas. O sistema realiza tal intento procurando interferir, por intermédio do planejamento administrativo escolar, na esfera cultural, fazendo com que esta, que tradicionalmente se reproduz por suas próprias condições e se orienta por critérios autolegitimadores, passe a depender da constituição e da legitimação sistêmica. Dessa forma, assuntos culturais e tradições, bases da educação, que se constituíam previamente em condições limítrofes paro o mundo sistêmico, acabam sendo incorporados à área do planejamento administrativo.

O diagnóstico do autor é que o planejamento administrativo passa a afetar crescentemente o sistema cultural, levando a escola a perder sua vinculação com o mundo da vida, deixando de ser um contexto de construção comunicativa dos conhecimentos e dos valores próprios da vivência dos alunos e professores. Ou seja, a escola perde a possibilidade de tornar-se um espaço público, em que os indivíduos desenvolvem a racionalidade do saber de forma participativa e aprofundam a solidariedade humana e a autonomia individual na convivência democrática entre todos. Ao invés de um espaço público de aprendizagem da convivência humana, torna-se, predominantemente, um lugar de aquisição de habilidades e de informações técnicas necessárias para a inserção do indivíduo no sistema do poder e do dinheiro.

De outra parte, à medida que vai desvinculando a educação do mundo da vida, a racionalidade sistêmica faz com que a educação desenvolva um papel ideológico que se torna comprometedor do ponto de vista epistemológico, a partir do 
momento em que passa a tratar os conhecimentos de forma neutra, impedindo que se torne explícito o processo histórico-social de sua constituição e a vinculação destes com as instâncias normativas e políticas. Habermas atesta isso quando escreve:

A eficácia peculiar desta ideologia reside em dissociar a autocompreensão da sociedade do sistema de referência da ação comunicativa e dos conceitos de interação simbolicamente mediada, e em substituí-lo por um modelo científico. Em igual medida, a autocompreensão culturalmente determinada de um mundo social de vida é substituída pela autocoisificação dos homens, sob as categorias da ação racional dirigida a fins e do comportamento adaptativo. (1994, p. 74)

Contudo, a influência mais nefasta da racionalidade sistêmica sobre a educação pode ser identificada nas consequências de sua transformação em mercadoria. Ao tornar-se mercadoria ou recurso de competitividade no processo produtivo capitalista, sua valorização passa a ser feita, prioritariamente, por critérios de lucratividade e eficiência, perdendo a sua conotação como valor epistemológico e como significação de valor social. Em outros termos, a educação passa a ser valorizada quase tão somente como recurso de ascensão econômica, ficando para um segundo plano sua validade enquanto recurso de qualificação subjetiva e de formação de uma visão social e política. Como diz Habermas, a monetarização faz com que tudo assuma ares de competividade mercantil:

À medida que o sistema econômico submete a seus imperativos a forma da vida doméstica e o modo de vida dos consumidores e trabalhadores, o consumismo e o individualismo possessivo relacionados com o rendimento e a competitividade assumem uma força configuradora. (1987b, p. 461)

Um dos prejuízos mais imediatos desta mercantilização da educação e da cultura é a perda da intimidade dos sujeitos com a obra cultural e a apropriação dos conhecimentos sem pressupostos rigorosos. A eliminação do rigor do conhecimento e a "facilitação psicologizante" com o objetivo de acesso e uso imediatos do saber empobrecem a experiência da conquista cultural. Habermas se dá conta disso ao fazer o seguinte comentário:

À medida que a cultura se torna mercadoria, e isso não só por sua forma, mas também por seu conteúdo, ela se aliena àqueles momentos cuja recepção exige uma certa escolarização - no que o "conhecimento" assimilado por sua vez eleva a própria capacidade de conhecer. Não já a estandardização enquanto tal, mas aquela pré-formação específica das obras criadas é que lhes empresta a maturidade para o consumo, ou seja, a garantia de poderem ser recebidas sem pressupostos rigorosos, certamente também sem consequências perceptíveis: isso coloca a comercialização dos bens culturais numa proporção inversa à sua complexidade. A intimidade com a cultura exercita o espírito, enquanto que o consumo da cultura de massas não deixa rastros; ele transmite uma espécie de experiência que não acumula, mas faz regredir. (Habermas, 1984, p. 196) 
Habermas percebe que o crescimento da intervenção sistêmica no campo da cultura e da educação produz perturbações, do ponto de vista da motivação e do sentido das ações dos envolvidos. A iniciativa sistêmica de introduzir uma orientação técnica e coercitiva na formação cultural e na educação tem levado ao esfriamento da relação pedagógica e provocado o surgimento de novas patologias no campo da motivação. A inclusão abstrata dos indivíduos em processos pedagógicos formais, que não levam em conta os indivíduos concretos, suas vivências e necessidades, seu mundo da vida, limita a interação dos indivíduos e dificulta a ação pedagógica do professor. Sob a orientação dos princípios sistêmicos, a socialização escolar transforma-se em um mosaico de atos administrativos e burocráticos que, geralmente, acabam se tornando inconsequentes e ineficazes. Um dos resultados mais imediatos é o entorpecimento do indivíduo nas suas relações organizacionais e o surgimento do fenômeno da perda do sentido e da motivação. Essas reações são consequências normais que, segundo o autor, "tornam consciente o fato de que não é possível produzir uma legitimidade cultural pela via administrativa" (Habermas, 1990, p. 102).

\section{A educação na perspectiva da racionalidade comunicativa: resistên- cia e emancipação}

Qual a possibilidade de se propor uma proposta de educação emancipadora neste contexto, em que progressivamente domina a racionalidade instrumental? Diante desse quadro, existe ainda espaço para uma educação humanizadora, crítica, transformadora? A teoria da racionalidade comunicativa apresenta alguma perspectiva de resistência ou de mudança diante deste contexto de colonização sistêmica?

Nossa compreensão é que tal potencial existe. Para tanto, porém, não se pode fazer uma análise simplificada das consequências que advêm da intervenção do sistema no contexto escolar. Ou seja, não basta propor, diante da constatação da predominância da racionalidade sistêmica, a simples substituição de uma orientação sistêmica pela orientação baseada nos princípios da racionalidade comunicativa; é preciso proceder a uma análise efetivamente crítica e transformadora de um contexto que, podemos concluir de antemão, jamais deixará de sofrer interferências das instâncias mencionadas. Nosso entendimento é de que, por meio da teoria da racionalidade comunicativa, pode-se instituir na escola um processo capaz de mediar racionalidade sistêmica e racionalidade comunicativa, cujo resultado será sempre uma síntese precária, suscetível à revisão permanente e à nova reconstrução.

O desafio lançado por Habermas aos educadores é de que esses se tornem críticos permanentes e incansáveis desta racionalidade sistêmica que começa a atingir a educação. Consciente de que a educação passa por um momento de crise, causada, 
em grande parte, pela incapacidade do sistema econômico de atender às expectativas e necessidades que ele mesmo cria, e ciente, também, do papel manipulador que o poder político exerce na dissimulação das causas desses conflitos, Habermas insiste em considerar que a humanidade pode retomar o projeto da modernidade e fazer da educação um processo de conscientização, auxiliando na instauração de uma sociedade mais justa, equilibrada e racional.

Ao fundamentar na interação comunicativa do mundo da vida a constituição da realidade social, Habermas procura resgatar um núcleo sadio e racional da humanidade que garante a resistência contra a colonização e a manutenção da possibilidade de emancipação. Isto implica afirmar que a humanidade, mesmo vivendo sob situações de opressão e de exploração - como é o caso da sociedade atual -, mantém condições que possibilitem a libertação. Tal potencialidade emancipatória vincula-se à restauração da comunicação livre de dominação presente no mundo da vida.

O mundo da vida constitui-se, portanto, em um conceito central na reconstrução que o autor propõe para as ciências sociais e para a educação. A redescoberta da natureza da racionalidade comunicativa não coagida, que se mantém agindo no mundo da vida, faz Habermas acreditar na possibilidade do progresso humano no sentido de sua libertação. Na racionalidade comunicativa que instaura o mundo da vida, ele identifica um elemento de resistência contra a dominação total da racionalidade sistêmica, instrumental. Essa resistência não é irracional, mimética, mas racional, utópica; ela não aponta para um retorno ao estado natural, mas para a possibilidade da realização de uma situação menos opressora na história, embora não possa definir a priori a forma de ser dessa nova ordem social.

A teoria de Habermas pode servir como uma referência para que os educadores repensem e mudem sua visão sobre o poder e o papel da educação no atual contexto social. O autor reacende a crença no poder da racionalidade humana, levando-nos a acreditar que a razão é capaz de reconstruir e superar as limitações de certas concepções produzidas por ela mesma. Para tanto, é preciso recuperar a experiência esquecida da reflexão, tornando a escola e, de modo especial, a sala de aula um espaço público de exercício do pensar, como condição necessária para a formação da opinião pública.

A teoria da racionalidade comunicativa aponta, ademais, para a necessidade de uma abordagem crítica e reconstrutiva da relação entre teoria e prática, tendo por referência a mediação que se configura entre estas duas dimensões sob a mediação da ação comunicativa. A crítica que o autor realiza acerca do reducionismo, produzido, especialmente, pela visão positivista e tecnicista da relação entre teoria e prática, pode ser um ponto de partida muito produtivo no desenvolvimento do conhecimento. Como aponta Habermas (1982), o positivismo, em nome de uma racionalidade monológica, instrumental, elimina a possibilidade de orientações racionais para a 
ação social dos indivíduos e desconhece o processo real da constituição do conhecimento humano. Renunciando a um conceito amplo e substancial de racionalidade, ele acaba destituindo a práxis de validade racional e, em nome da neutralidade, desconsiderando as influências das necessidades e dos interesses na constituição histórica dos conhecimentos. Com isso, o positivismo promove uma separação instransponível entre teoria e práxis e reduz o conhecimento racional a um emaranhado de orientações e procedimentos técnicos. Retomar a relação teoria-prática implica desvelar os limites impostos pelo desenvolvimento do conhecimento atrelado aos interesses restritos dos grupos políticos e econômicos dominantes e, ao mesmo tempo, explicitar sob que aspectos o conhecimento se vincula a interesses antropológicos e aos desejos da emancipação da humanidade. Ou seja, a práxis atual exige tanto o desenvolvimento da crítica ao reducionismo produzido pela visão positivista de racionalidade, como a reconstrução de uma visão ampliada de racionalidade que a teoria da interação comunicativa pode oferecer.

Habermas considera que não basta denunciar o caráter reducionista do positivismo e mostrar a unidimensionalidade que o mesmo apresenta quanto à relação teoria-prática. É preciso lançar-se na tarefa de buscar uma nova mediação entre elas. Para tanto, ele procura apoio numa filosofia crítica que coloca sob suspeita a visão monológica do pensar e agir científicos e passa a compreendê-los dentro de um quadro em que todo o conhecimento submete-se, continuamente, à reavaliação, tendo por base não somente o terreno da justificação lógica e da eficiência técnica, mas os possíveis efeitos de seu agir sobre a vida prática dos homens.

A retomada da relação teoria-prática dá-se, na concepção habermasiana, pelo reacoplamento da ciência e da técnica ao mundo da vida, instância do agir comunicativo. A leitura da relação entre ambas é feita pela lógica do mundo da vida, tendo por referencial o método hermenêutico, reconstrutivo, crítico. Este método se define pela sua umbilical relação com a práxis do mundo da vida, com o significado prático da razão humana que se constitui historicamente. Em outros termos, é um método que entende a relação teoria-prática como práxis comunicativa, como um processo concreto que é vivenciado, de forma efetiva, na vida diária de cada indivíduo, motivado por interesses e necessidades naturais e histórico-sociais.

Essa concepção da relação teoria-prática como práxis comunicativa nos parece muito desafiadora para a educação, uma vez que, além de oferecer elementos teórico-práticos para que a educação possa atingir seus objetivos de envolver efetivamente alunos e professores em um processo coletivo de construção dos conhecimentos e de personalidades comprometidas com o seu contexto social, faz com que se restabeleça a unidade dialética entre teoria e prática, bem como o sentido ético e político do processo pedagógico. Isso possibilita que as diversas modalidades de conhecimentos e os valores dos grupos sociais sejam reacoplados ao julgamento do 
mundo da vida e legitimados pela participação de todos em tal processo, através de discursos em que a comunicação não distorcida se mantém intacta.

Em síntese, vislumbramos o restabelecimento da perspectiva emancipadora da educação, à medida que essa passa a assumir um papel reconstrutivo e crítico em relação aos conhecimentos e aos valores existentes, exercendo a função de uma ciência reconstrutiva, cuja função social destina-se a promover a descolonização do mundo da vida. Conforme Habermas, nessa perspectiva, cabe à filosofia e, em decorrência, à educação um papel determinante de "conferir autoridade epistêmica à comunidade daqueles que cooperam e falam uns com os outros" (Habermas, 1989, p. 33), contribuindo com a reconstrução do sentido da existência humana pela superação das patologias provocadas pela comunicação sistematicamente distorcida - neuroses e ideologias - e pelo restabelecimento da primazia do mundo da vida na determinação da validade dos conhecimentos e das normas sociais.

\section{Racionalidade comunicativa e emancipação: o papel da filosofia.}

Nesse processo reconstrutivo da racionalidade, base para a retomada da perspectiva crítica e transformadora da educação, a filosofia - neste caso específico, a filosofia da educação - assume um novo papel. Habermas (1989) assevera que a filosofia não tem mais o poder que a tradição lhe atribuía de oferecer um conhecimento totalizador e fundamentador, nem tem a função profética de prever um futuro e de esclarecer quais as condições que devem ser criadas para que esse futuro se realize. Não lhe cabe, além disso, o papel de mera crítica externa da vida social e, muito menos, de responsável pela reconstrução da lógica da ciência, como querem os neopositivistas. Em síntese, ela deixa de ter o papel de juíza e de indicadora de lugar, para assumir o papel mais modesto de intérprete-mediadora. Acima de tudo, ela precisa tornar-se ciente dos seus próprios limites sem negar suas potencialidades.

No campo específico da educação, a filosofia não pode pretender ser a ciência responsável pelo estabelecimento claro e indiscutível dos fins e dos princípios pedagógicos que devem orientar o processo educacional e nem ter a pretensão de ser a juíza das demais ciências e dos demais campos do saber; ela precisa deixar de ser entendida como ciência dos primeiros princípios e como a base de fundamentação última de todos os saberes e fazeres humanos. De outra parte, ela também não pode ser reduzida à mera literatura, à ficção ou à função poética, como apregoam alguns intelectuais pós-modernos.

A filosofia deve manter-se vinculada a uma noção mais ampla de racionalidade e ocupar-se com a questão da unidade da razão, hoje tão fragmentada e reduzida pela predominância de uma visão instrumentalista do conhecimento. Cabe-lhe 
delimitar uma concepção mínima de racionalidade e de esclarecer as confusões que determinadas concepções de conhecimento - inclusive dela própria - têm provocado na humanidade. Sua tarefa é restabelecer a própria unidade na diversidade de suas manifestações, não negando a multiplicidade das suas expressões, nem aceitando a visão reducionista a que o relativismo, o positivismo e o neopragmatismo querem submetê-la. Em outros termos, seu atributo é esclarecer os fundamentos racionais do agir, do pensar e do falar humanos, explicitando o telos emancipatório que se mantém presente em todo que-fazer dos indivíduos, e mediar a cultura dos especialistas com o mundo da vida.

Todos os saberes, por mais falíveis que possam ser, só assumem a condição de saberes válidos quando justificados por argumentos racionais. $\mathrm{O}$ argumento reconhecido pela comunidade comunicativa como o melhor é o critério último de validação de qualquer saber, seja ele científico, prático ou estético. Por isso, o problema da validação torna-se, no entender do autor, o tema fundamental da filosofia. Em consequência, na teoria comunicativa a filosofia passa a assumir a função de intérprete mediadora, devendo interagir, sem discriminações e dogmatismos, com todos os campos do saber, com a pretensão de racionalizar todas as instâncias do pensar e agir da humanidade pelo processo da validação baseado em argumentos. Nas palavras do próprio autor,

Racionalizar significa aqui o cancelamento das relações de coerção que, penetrando imperceptivelmente nas estruturas comunicativas, impedem - através de bloqueios intrapsíquicos e intrapessoais da comunicação - que os conflitos sejam afirmados conscientemente e regulamentados de modo consensual. Racionalizar significa a superação de tal comunicação sistematicamente distorcida, na qual o consenso relativo às pretensões de validade reciprocamente colocadas - que servem como suporte à ação -, sobretudo o consenso acerca da veracidade das exteriorizações intencionais e sobre a justeza das normas de base, é conservado de pé só aparentemente, ou seja, como uma contrafação. ( Habermas, 1990, p. 34)

Para Habermas, a filosofia deve exercer um duplo papel: de um lado, ela precisa constituir-se em uma teoria crítica da sociedade e, de outro, promover o processo de cooperação interdisciplinar. Ou seja, a filosofia tem a função de mediar a relação entre o processo de entendimento presente no mundo da vida e os conhecimentos promovidos pelas diversas instâncias do saber.

A filosofia, enquanto voltada à racionalização do mundo da vida, constitui-se em um saber pragmático e falível: pragmático, porque lhe cabe provar que existem pressupostos universais e inevitáveis do entendimento que interferem, de forma efetiva, no agir humano; falível, porque até mesmo esses pressupostos são passíveis de contestação ou de superação. Embora devamos concordar que as pretensões de validade inerentes aos atos de fala e ao discurso são sempre admitidas como quase infalíveis 
enquanto condições de possibilidade do entendimento humano, não temos nenhuma prova definitiva que nos garanta tal infalibilidade; nada garante que a nossa argumentação possa ser desmentida . Esse é o motivo que leva Habermas a não admitir a tese de uma fundamentação última da verdade. A verdade é fruto da reconstrução do próprio processo de desenvolvimento da argumentação que os indivíduos realizam ao colocarem sob julgamento qualquer proposição. Assim, a explicitação de todo e qualquer conhecimento é hipotética e a confirmação ou negação da sua validade dependem do acordo a que chega uma comunidade de falantes em comunicação. Nessa perspectiva, a filosofia assume uma função apenas indiretamente legisladora, pois aponta tão somente para os desvios no cumprimento das condições de possibilidade do entendimento. Ela já não tem o poder de fundamentar as atividades dos homens, ficando sua tarefa limitada à função justificadora da racionalidade que se apresenta na história. Em decorrência, como já afirmamos anteriormente, um dos desafios preliminares da filosofia em Habermas é reconstruir o conceito de razão incorporada no agir comunicativo, identificando sua incondicionalidade e, ao mesmo tempo, sua suscetibilidade crítica. O papel da filosofia é desenvolver um conceito de racionalidade que, ao mesmo tempo, conteste o fundamentalismo e o relativismo. Para tanto, a filosofia deve assumir uma postura reconstrutiva e interagir com as diversas instâncias das ciências, assumindo uma postura metodológica semelhante à das demais ciências:

\footnotetext{
Em primeiro lugar temos que ter presente que a filosofia muda de papel quando passa a cooperar com as ciências. Ao fazer seu aporte a uma teoria da racionalidade, participa de uma divisão de trabalho com ciências que procedem reconstrutivamente, isto é, ciências que partem do saber pré-teórico de sujeitos que julgam, atuam e falam competentemente e também dos sistemas de saber coletivos legados pela tradição e cujo propósito é apreender as bases da racionalidade da experiência e do juízo, da ação e do entendimento linguístico. Também as reconstruções empreendidas com meios filosóficos mantêm neste contexto um caráter hipotético; por causa, precisamente, de sua forte pretensão universalista, se vêem remetidas a ulteriores comprovações de tipo indireto. (Habermas, 1987b, p. 566)
}

A filosofia deixa de ter, portanto, a função de orientar as demais ciências, passando a ser tão somente uma colaboradora com estas na reconstrução da racionalidade que lhes é implícita. Sua tarefa é apontar para os potenciais e para os desvios no cumprimento das condições de possibilidade do entendimento, não tendo, porém, o poder de estabelecer uma fundamentação última dos saberes. Porém, enquanto as ciências vinculadas ao empírico tratam de questões de gênese, a filosofia trata de questões de justificação.

No que tange especificamente à educação, cabe à filosofia ajudar a revelar as pressuposições e os procedimentos implícitos nos diversos campos do saber, bem como esclarecer os conhecimentos intuitivos que, em geral, determinam o agir e pensar de professores e alunos. A filosofia assume o papel de guardiã da racionalidade 
comunicativa, promovendo a crítica do agir pedagógico e vigiando para que o espaço público do discurso em sala de aula se mantenha acessível a todos os concernidos; ela deve zelar para que o espaço da racionalidade e do mundo da vida não seja apropriado pela racionalidade instrumental e estratégica do mundo sistêmico no contexto escolar.

\section{Conclusão}

A exploração das ideias habermasianas no campo educacional nos parece bastante produtiva. Embora Habermas não se ocupe, especificamente, do problema da educação em seus trabalhos, ao voltar-se ao problema da racionalidade e realizar uma nova leitura da teoria da modernidade, procurando explicitar o processo de evolução social em todas as suas contradições e potencialidades, ele apresenta referenciais importantes para o entendimento dos problemas que atingem a formação da sociedade contemporânea.

A tese de Habermas é que a emancipação humana não depende de qualquer tipo de determinismo transcendental ou técnico-instrumental. Esta só poderá realizar-se quando estiver vinculada à formação da vontade democrática por intermédio da esfera pública e de processos de libertação dos discursos de todos os indivíduos envolvidos. Para tanto, pondera o autor, a crítica deve lançar-se contra a ideologia reducionista da racionalidade humana através da destruição da ilusão objetivista, mostrando que todo o nosso conhecimento já se encontra sempre referido a um horizonte prévio de compreensão e de interpretação intersubjetivo no seio da linguagem comum presente no mundo da vida e que, além do interesse técnico, a humanidade age também motivada por interesses práticos e emancipadores.

A introdução da visão da interdependência dos interesses condutores do agir e pensar humanos é a base para o desenvolvimento de uma educação voltada à formação integral de alunos e professores e para transformar a escola em uma comunidade pedagógica, comunicativa. Para tanto, a escola é desafiada a promover a reflexão sobre os pressupostos e os interesses que estão na base dos conhecimentos e das práticas que desenvolve cotidianamente, possibilitando que toda a comunidade escolar se torne uma organização que fundamente suas ações científicas, éticas e estéticas na prática comunicativa. É na prática cotidiana da comunicação, na busca do entendimento sem coação, que se configura o processo de libertação da humanidade, pois esta continua a depender da inteligibilidade e da decisão coletiva baseada em argumentos racionais.

Habermas é um pensador que mantém a esperança no poder emancipador e na função esclarecedora da racionalidade humana. Ainda que admita que atualmente 
a racionalidade instrumental e a educação se tornaram mecanismos de opressão e de obliteração da dignidade da vida humana, ele entende que nem toda educação é opressora e que nem todo saber é necessariamente destrutivo. Ou seja, razão não é exclusivamente instrumento de dominação e exploração; mesmo em um mundo que em que cresce a racionalidade sistêmica, a razão continua mantendo um potencial emancipatório. Ou seja, o caminho da razão continua passando pela própria razão, pois, ainda que já não se possa mais falar de conceitos fortes de teoria e de fundamentação última da verdade, isso não implica concluir que possamos abrir mão desta mesma razão para assegurar a validade de nossas críticas e alimentar nossas expectativas sobre a possibilidade futura da humanidade.

Nesse contexto, o autor atribui um papel fundamental à filosofia: "gostaria finalmente de defender a tese de que a filosofia, mesmo quando se retrai dos papeis problemáticos de indicador de lugar e do juiz, pode - e deve - conservar sua pretensão de razão nas funções mais modestas de um guardador de lugar e de um intérprete" (Habermas, 1989, p. 20). No papel de intérprete-mediadora, cabe-lhe, prioritariamente, atualizar sua relação com a totalidade pela reflexão sobre o mundo da vida, procurando restabelecer os potenciais de emancipação que nele se fazem presentes e pela crítica aos mecanismos de colonização que a ele se pretende impor. Sob esta perspectiva, sua tarefa é restaurar a comunicação e promover o entendimento pela interação comunicativa. Ao lado desta função, ela deve exercer o papel de guardiã da racionalidade, entabulando conversações com as diferentes áreas do saber, procurando promover a integração destes diferentes domínios com a moral e a arte. Em síntese, como guardadora de lugar e de intérprete, cabe-lhe assegurar uma abertura permanente de todos os saberes na busca de fundamentos universais capazes de justificar os conhecimentos e as ações diante de todos os concernidos.

\section{Referências}

HABERMAS, J. Conhecimento e interesse. Rio de Janeiro: Zahar, 1982.

HABERMAS, J. Mudança estrutural da esfera pública. Rio de Janeiro: Tempo Brasileiro, 1984.

HABERMAS, J. Teoría de la acción comunicativa I: racionalidad de la acción y racionalización social. Madrid: Taurus, 1987a.

HABERMAS, J. Teoría de la acción comunicativa II: crítica de la razón funcionalista. Madrid: Taurus, 1987b.

HABERMAS, J. Consciência moral e agir comunicativo. Rio de Janeiro: Tempo Brasileiro, 1989. 
Habermas e a educação: racionalidade comunicativa, diagnóstico crítico e emancipação

HABERMAS, J. Para a reconstrução do materialismo histórico. 2. ed. São Paulo: Brasiliense, 1990.

HABERMAS, J. Técnica e ciência como ideologia. Lisboa: Dom Quixote, 1994.

HABERMAS, J. A crise de legitimação do capitalismo tardio. 2. ed. Rio de Janeiro: Tempo Brasileiro, 1995.

HABERMAS, J. Teoría de la acción comunicativa: complemientos y estudios prévios. Madrid: Cátedra, 1997.

HABERMAS, J. Discurso filosófico da modernidade. São Paulo: DIFEL, 2000.

Recebido em 16 de junho de 2009.

Aprovado em 24 de novembro de 2009. 